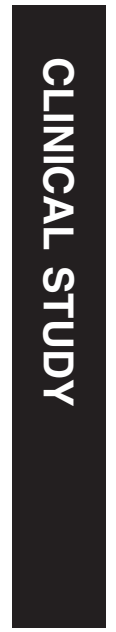

'Dept of Opthalmology Gazi University Medical Faculty

Ankara, Turkey

${ }^{2}$ Dept of Pathology Gazi University Medical Faculty

Ankara, Turkey

Correspondence: B Hasanreisoglu Selanik cad No: 23/13

Kizilay

Ankara, Turkey

Fax: 903122125794

E-mail: gurelik@

rocketmail.com

Received: 14 December 2000;

Accepted in revised form: 14 August 2001

\section{Effect of mechanical vs dilute ethanol epithelial removal on keratocyte apoptosis and polymorphonuclear
leukocyte migration}

\author{
Abstract \\ Purpose To investigate keratocyte apoptosis \\ and polymorphonuclear (PMN) cell \\ infiltration to the corneal stroma after \\ mechanical epithelial scraping and chemical \\ de-epithelialization with $18 \%$ ethanol \\ solution.
}

Methods Twelve New Zealand Albino rabbits ( 24 eyes) were randomly divided into three groups. Group A was the control group with no epithelial removal. Group B underwent a 7.5-mm mechanical epithelial removal with a blunt spatula. Group C underwent $7.5-\mathrm{mm}$ chemical deepithelialization with $18 \%$ ethanol-balanced salt solution. Corneas were stained with terminal deoxyribonucleotidyl transferasemediated dUTP-digoxigenin nick-end labeling (TUNEL) assay after $24 \mathrm{~h}$. Only nuclear staining in keratocytes was counted. Polymorphonuclear (PMN) leukocyte densities were also assessed by light microscopy.

Results Mechanical de-epithelialization (group B) and chemical de-epithelialization with $18 \%$ ethanol (group C) showed no difference in keratocyte apoptosis compared with the control group. There was also no difference between groups B and C. Group B showed no difference in PMN leukocyte counts compared with the control group. But the number of PMN leukocytes observed in group $C$ was significantly higher than those encountered in the corneas of the control group $(P<0.05)$ and group $B(P<0.05)$. Conclusions Dilute alcohol induces more PMN cell infiltration when compared with mechanical de-epithelialization although there is no difference in the apoptosis rates.
G Gurelik¹, K Bilgihan¹, C Sezer², G Akyol² and B Hasanreisoglu ${ }^{1}$
Eye (2002) 16, 136-139. DOI: 10.1038/

sj/EYE/6700074

Keywords: epithelial removal; keratocyte apoptosis; polymorphonuclear leukocyte

Introduction

Removal of corneal epithelium causes loss of superficial stromal keratocytes in rabbits and monkeys. ${ }^{1,2}$ Previous studies have demonstrated that anterior corneal keratocytes undergo apoptosis in response to mechanical and chemical deepithelialization with concentrated ethanol solutions. ${ }^{3-5}$ In the clinical studies chemical de-epithelialization with dilute ethanol $(18 \%$ or $20 \%)$ has been found to be a simple, safe, fast and effective alternative to mechanical epithelial scraping before photorefractive keratectomy (PRK). ${ }^{6,7}$ Smoother Bowman's layer surface and sharper edges have been observed after chemical deepithelialization with $18 \%$ or $20 \%$ ethanol solution and the better clinical results in terms of haze and corneal regularity have been explained with these findings. ${ }^{7,8}$ But the keratocyte apoptosis has not been investigated after chemical de-epithelialization with dilute ethanol up to now.

In the present study keratocyte apoptosis and polymorphonuclear (PMN) cell infiltration to the corneal stroma is investigated qualitatively and quantitatively after mechanical epithelial scraping and chemical de-epithelialization with $18 \%$ ethanol solution. 


\section{Materials and methods}

Twelve New Zealand Albino rabbits (24 eyes) were randomly divided into three groups each containing four rabbits (eight eyes). Accepted principles of animal maintenance and care were conformed to in the present study. A control group is designed in the study to find out if any of the epithelial removal groups differ in keratocyte apoptosis and polymorphonuclear leukocyte migration when compared to normal rabbit corneas, and may suggest one of the epithelial removal methods to be less traumatic to the corneal stroma according to the results.

The rabbits were anesthetized with an intramuscular injection of ketamine hydrochloride $(40 \mathrm{mg} / \mathrm{kg}$ ) and xylazine hydrochloride $(7 \mathrm{mg} / \mathrm{kg})$. Group A was the control group with no epithelial removal. Group B rabbits underwent a 7.5-mm mechanical epithelial removal with a blunt spatula. Group C rabbits underwent 7.5-mm chemical de-epithelialization with $18 \%$ ethanol-balanced salt solution soaked in a synthetic sponge and applied for $20 \mathrm{~s}$. After the application, the corneal surface was dried using synthetic sponges. The eye was then copiously irrigated with balanced salt solution to wash out residual alcohol remnants, and the melted epithelium was removed using dry sponges.

Animals were euthanized with $100 \mathrm{mg} / \mathrm{kg}$ intravenous pentobarbital injection, $24 \mathrm{~h}$ following corneal surgery. The eyes were enucleated and central corneal tissues were removed by using a $7.5-\mathrm{mm}$ trephine and fixed in $10 \%$ formaldehyde solution for $2 \mathrm{~h}$, then embedded vertically in paraffin. Full thickness sections were taken from different levels of $4 \mu \mathrm{m}$. Following deparaffinisation proteinase $\mathrm{K}$ (Applipere, Oncor 130202) was applied for $15 \mathrm{~min}$. The corneas were stained according to the manufacturer's instructions with terminal deoxyribonucleotidyl transferase-mediated dUTP-digoxigenin nick-end labeling (TUNEL) assay by using ApopTag plus peroxidase in situ apoptosis detection kit (S-7101, Oncor). Counterstaining of the specimens was made in $0.5 \%$ methyl green. Rat breast tissue was used as a positive control material. Only nuclear staining in keratocytes was counted; four sections from each specimen were evaluated by light microscopy at higher magnification fields $(\times 400)$. PMN leukocyte densities were also assessed by light microscopy on all sections at higher magnification fields $(\times 400)$ with hematoxylineosin staining. The mean values of 40 different fields of each specimen were calculated.

Anova analysis was used to compare the results
Table 1 Results of the keratocyte apoptosis counts in the control group and epithelial removal groups

\begin{tabular}{lccc}
\hline Groups & $\begin{array}{c}\text { Apoptosis } \\
(\text { mean } \pm S D)\end{array}$ & Anova test* & $P$ value** \\
\hline $\begin{array}{l}\text { Group A } \\
\text { (control) }\end{array}$ & $0.012 \pm 0.031$ & & \\
$\begin{array}{l}\text { Group B } \\
\text { (mechanical) }\end{array}$ & $2.55 \pm 3.05$ & 0.473 & $P>0.05$ \\
$\begin{array}{l}\text { Group C (18\% } \\
\text { ethanol) }\end{array}$ & $6.0 \pm 10.79$ & 0.101 & $P>0.05$ \\
\hline
\end{tabular}

*Anova test results show comparisons of Group B and C with Group A (control group)

**Significiant $P$ value: $P<0.05$.

obtained in all groups and an overall $P<0.05$ was considered to be significant.

\section{Results}

The results of the keratocyte apoptosis counts in the control group and epithelial removal groups are summarized in Table 1. Mechanical de-epithelialization (group B) and chemical de-epithelialization with 18\% ethanol (group C) showed no difference in keratocyte apoptosis compared with the control group (group A). There was also no difference between groups B and C.

The results of the PMN leukocyte counts in the control group and epithelial removal groups are summarized in Table 2. Mechanical de-epithelialization (group B) showed no difference in PMN leukocyte counts compared with the control group (group A). But the number of PMN leukocytes observed in chemical de-epithelialization with 18\% ethanol (group $C)$ was significantly higher than those encountered in the corneas of the control group $(P<0.05)$ and the mechanical de-epithelialization group $(P<0.05)$ (Figures 1 and 2).

Table 2 Results of the polymorphonuclear leukocyte counts in the control group and epithelial removal groups

\begin{tabular}{lccc}
\hline Groups & $\begin{array}{l}\text { PMN counts } \\
(\text { mean } \pm \text { SD) }\end{array}$ & Anova test* & P value** \\
\hline $\begin{array}{l}\text { Group A } \\
\text { (control) }\end{array}$ & $0.33 \pm 0.35$ & & \\
$\begin{array}{l}\text { Group B } \\
\text { (mechanical) }\end{array}$ & $1.99 \pm 1.36$ & 0.286 & $P>0.05$ \\
$\begin{array}{l}\text { Group C (18\% } \\
\text { ethanol) }\end{array}$ & $11.71 \pm 4.68$ & 0.00 & $P<0.005$ \\
\hline
\end{tabular}

*Anova test results show comparisons of Group B and C with Group A (control group).

**Significiant $P$ value: $P<0.05$. 


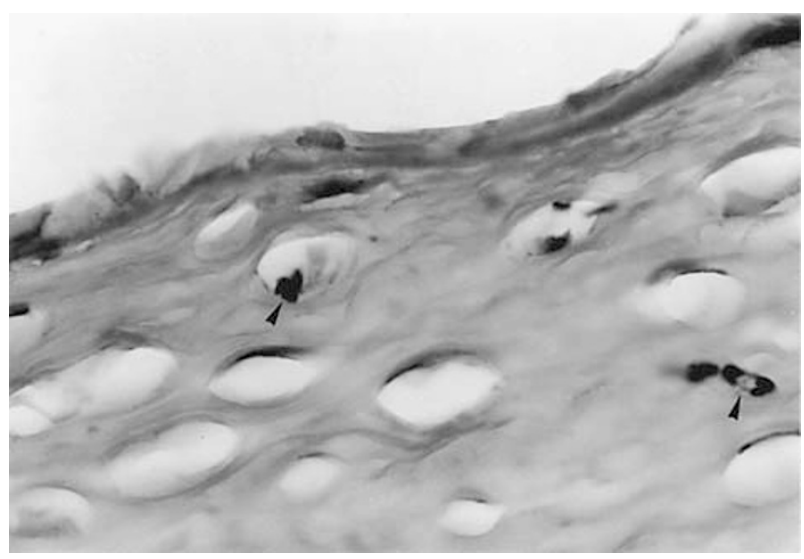

Figure 1 PMN leukocytes in the mechanical epithelial removal group (arrows) by light microscopy (HE 1000×).

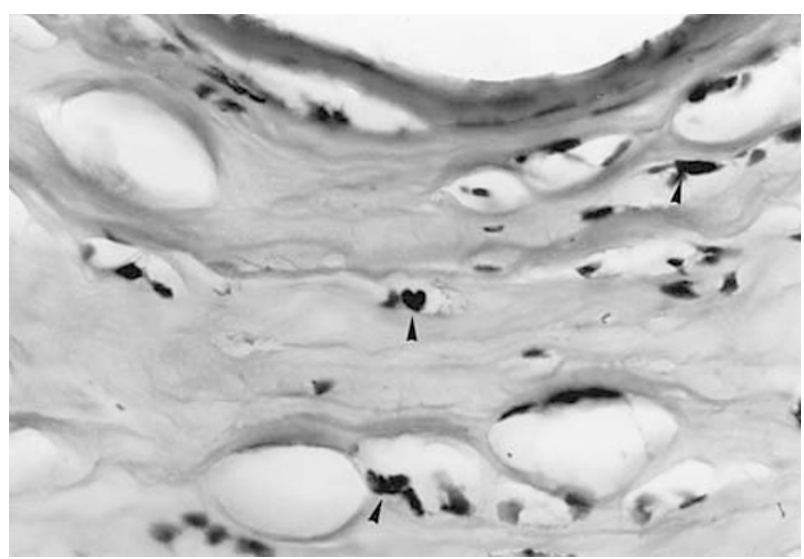

Figure 2 PMN leukocytes in the dilute alcohol epithelial removal group (arrows) by light microscopy (HE 1000×).

\section{Discussion}

A consistent degree of keratocyte loss is observed in rabbit and monkey corneas after de-epithelialization using mechanical means, chemicals or the excimer laser. ${ }^{1,2}$ Apoptosis is a different way of cell death from ordinary cell death. It is a programmed, complex and controlled death of a cell without damage to surrounding tissue and, in contrast to ordinary cell death, there is no incitement of inflammatory reaction. ${ }^{9-14}$ But the induction of apoptosis by reactive oxygen species has been demonstrated in recent studies. ${ }^{15,16}$ PMN leukocyte infiltration of the corneal stroma after PRK has been demonstrated in many studies. ${ }^{17,18}$ PMN leukocyte infiltration in the superficial corneal stroma might be responsible for the lipid peroxidation after PRK. ${ }^{2}$ Free oxygen radicals are toxic products and may be responsible for some of the complications of the excimer laser corneal surgery. ${ }^{18-20}$ Nitric oxide (NO) is a diffusible free radical gas and is formed in large amounts by the inducible nitric oxide synthase in PMN leukocytes and other cell types stimulated by inflammatory cytocines. NO reacts extremely rapidly with superoxide to form the peroxynitrite. ${ }^{21}$ Peroxynitrite, the reaction product of superoxide and NO, may be a major cytotoxic agent produced during inflammation; peroxynitrite is a highly reactive molecule and induces lipid peroxidation ${ }^{22,23}$ and antioxidant therapy may have a role in diminishing oxidative damage. ${ }^{24}$ Therefore the amount of PMN cell infiltration into the corneal stroma may be an indicator of tissue damage which induces corneal wound healing, haze and regression. The question of whether different de-epithelialization techniques may induce different healing responses and keratocyte apoptosis, and consequently different clinical results is still controversial. Various methods of de-epithelialization induce significant stromal acute inflammation 1 day after surgery compared with normal corneas. ${ }^{1}$

De-epithelialization with $50 \%$ and higher concentrations of ethanol causes more keratocyte loss with perhaps more corneal edema, but less stromal influx of neutrophils, than does a mechanical technique $24 \mathrm{~h}$ after PRK in rabbit models and clinical trials. ${ }^{1,3}$ Corneal de-epithelialization with $20 \%$ dilute alcohol was shown to provide sharper edges and a smoother Bowman's layer surface than mechanical debridement which may explain the better results in terms of haze and corneal regularity. ${ }^{8}$ Corneal de-epithelialization with dilute ethanol may be a viable option in PRK and that is why dilute alcohol (18\% ethanol) was used for chemical de-epithelialization in our study. There was no significant difference in keratocyte apoptosis between mechanical de-epithelialization and 18\% ethanol de-epithelialization but the amount of PMN cell infiltration was significantly higher $(P<0.05)$ in $18 \%$ ethanol compared with mechanical deepithelialization in the present study.

We attempted here to evaluate the more common clinically used de-epithelialization methods and examine their effects on keratocyte apoptosis and stromal inflammation which is also related to keratocyte survival. Dilute alcohol (18\% ethanol) may be used for corneal de-epithelialization but it seems that it induces more PMN cell infiltration compared with mechanical de-epithelialization although there is no difference in the apoptosis rates.

\section{References}

1 Campos M, Raman S, Lee M, McDonnell PJ. Keratocyte loss after different methods of de-epithelialization. Ophthalmology 1994; 101: 890-894.

2 Campos M, Szerenyi K, Lee M, McDonnell JM, Lopez PF, McDonnell PJ. Keratocyte loss after corneal 
deepithelialization in primates and rabbits. Arch Ophthalmol 1994; 112: 254-260.

3 Helena MC, Filatov VV, Johnston WT, Vidaurri-Leal J, Wilson SE, Talamo JH. Effects of 50\% ethanol and mechanical epithelial debridement on corneal structure before and after excimer photorefractive keratectomy. Cornea 1997; 16: 571-579.

4 Wilson SE. Everett Kinsey Lecture. Keratocyte apoptosis in refractive surgery. CLAO J 1998; 24: 181-185.

5 Helena MC, Baerveldt F, Kim WJ, Wilson SE. Keratocyte apoptosis after corneal surgery. Invest Ophthalmol Vis Sci 1998; 39: 276-283.

6 Abad JC, An B, Power WJ, Foster CS, Azar DT, Talamo $\mathrm{JH}$. A prospective evaluation of alcohol-assisted versus mechanical epithelial removal before photorefractive keratectomy. Ophthalmology 1997; 104: 1566-1574.

7 Abad JC, Talamo JH, Vidaurri-Leal J, Cantu-Charles C, Helena MC. Dilute ethanol versus mechanical debridement before photorefractive keratectomy. J Cataract Refract Surg 1996; 22: 1427-1433.

8 Carones F, Fiore T, Brancato R. Mechanical vs alcohol epithelial removal during photorefractive keratectomy. J Refract Surg 1999; 15: 556-562.

9 Wilson SE, HE Y-G, Weng J et al. Epithelial injury induces keratocyte apoptosis: hypothesized role for the interleukin-1 system in the modulation of corneal tissue organization and wound healing. Exp Eye Res 1996; 62: 325-338.

10 Wilson SE. Programmed cell death, wound healing, and laser refractive surgical procedures: molecular-cell biology for the corneal surgeon. J Refract Surg 1997; 13: 171-175.

11 Kim W-J, Shah S, Wilson SE. Differences in keratocyte apoptosis following transepithelial and laser-scrape photorefractive keratectomy in rabbits. J Refract Surg 1998; 14: 526-533.

12 Wilson SE, Li Q, Weng J et al. The Fas/Fas ligand system and other modulators of apoptosis in the cornea. Invest Ophthalmol Vis Sci 1996; 37: 1582-1592.
13 Krueger RR. Could apoptosis change the way we do PRK? J Refract Surg 1998; 14: 494-496.

14 Wilson SE. Stimulus-specific and cell type-specific cascades: emerging principles relating to control of apoptosis in the eye. Exp Eye Res 1999; 69: 255-266.

15 Shimmura S, Masumizu T, Nakai Y et al. Excimer laser induced hydroxyl radical formation and keratocyte death in vitro. Invest Ophthalmol Vis Sci 1999; 40: 1245-1249.

16 Cho KS, Lee EH, Choi JS et al. Reactive oxygen species induced apoptosis and necrosis in bovine corneal endothelial cells. Invest Ophthalmol Vis Sci 1999; 40: 911919.

17 Phillips AF, Szerenyi K, Campos M et al. Arachidonic acid metabolites after excimer laser corneal surgery. Arch Ophthalmol 1993; 111: 1273-1278.

18 Hayashi S, Ishimoto S, Wu G, Wee W, Rao N, McDonnell $\mathrm{P}$. Oxygen free radical damage in the cornea after excimer laser therapy. Br J Ophthalmol 1997; 81: 141-144.

19 Kasetsuwan N, Wu FM, Hsieh F et al. Effect of topical ascorbic acid on free radical tissue damage and inflammatory cell influx in the cornea after excimer laser corneal surgery. Arch Ophthalmol 1999; 117: 649-562.

20 Bilgihan K, Bilgihan A, Akata F, Turkozkan N, Hasanreisoglu B. Excimer laser corneal surgery and free oxygen radicals. Jpn J Ophthalmol 1996; 40: 154-157

21 Beckman JS, Beckman T, Chen J et al. Apparent hydroxyl radical production by peroxynitrite: implications for endothelial injury from nitric oxide and superoxide. Proc Natl Acad Sci USA 1990; 87: 1620-1624.

22 Misko TP, Highkin MK, Veenhuizen AW, Manning PT, Stern MK, Currie MG, Salvemini D. Characterization of the cytoprotective action of peroxynitrite decomposition catalysts. J Biol Chem 1988; 273: 15646-15653.

23 Moilanen E, Vapaatalo H. Nitric oxide in inflammation and immune response. Ann Med 1995; 27: 359-367.

24 Bilgihan K, Adiguzel U, Sezer C, Akyol G, Hasanreisoglu B. Effects of topical vitamin $\mathrm{E}$ on keratocyte apoptosis after traditional photorefractive keratectomy. Ophthalmologica 2001; 215: 192-196. 